\title{
Attempts towards a sustainable motorway development in Greece
}

\author{
A. Kokkalis ${ }^{1} \& \mathrm{~S}$. Basbas ${ }^{2}$ \\ ${ }^{1}$ Democritus University of Thrace, Greece \\ ${ }^{2}$ Aristotle University of Thessaloniki, Greece
}

\begin{abstract}
2,000 $\mathrm{km}$ of motorway network are currently under design and construction in Greece and comprise the completion of the mainland motorway network. Environmental impacts are inherent in all major transportation infrastructure projects. The appropriate framework should exist to safeguard and maintain most environmental parameters so that sustainable development is attained. The general target should always be that the negative environmental burden due to a transportation project should never exceed the carrying capacity of the local environment so that ecological sustainability would not be endangered. The first step in implementing an integrated environmental policy is the determination of all possible impacts and the evaluation of their relevant severance. All sectors should be appraised, such as air quality, water, soil, nuisance, landscape, ecological and cultural severance. The environmental impacts of a project have to be assessed from the earliest possible stage. Parameters at the definitive design study and activities at the construction phase of the project have to comply with a specifically issued detailed Ministry Environmental Decree. The Decree is valid for a certain period of time and for the specific area of the project. An application case to Egnatia motorway is outlined. Specific Landscape Guidelines have been issued which comprise a Landscape Strategy for the whole road - the commitment to treat the landscape along the road corridor and associated link roads.
\end{abstract}

Keywords: roadworks, environmental appraisal, environmental terms, sustainable development. 


\section{Introduction}

The road transportation sector plays a fundamental role in post-industrial society organization and is continually developing contributing to the economic integration of most countries. Approximately $45 \%$ of goods are transported through roads in Greece, a figure expected to rise even more [1]. Many road transportation projects are under design or completion to make up for that increasing demand.

Negative environmental impacts are inherent in all transportation projects. The theoretic target should be that the project burden would never exceed the carrying capacity of the environment so that ecological sustainability would not be endangered. The appropriate framework should exist to safeguard and maintain most environmental parameters.

\section{Environmental impacts identification and appraisal}

The first step in implementing an integrated pro-environmental policy is the determination of all possible impacts. Environmental impacts of major road transportation projects are summarized in Table 1, Kokkalis and Basbas [2].

Table 1: $\quad$ Potential environmental impacts of roadworks.

\begin{tabular}{|l|l|}
\hline Sector & Potential Environmental Impacts \\
\hline 1. Air & dust by construction traffic \& vehicle emissions \\
\hline 2. Water & $\begin{array}{l}\text { Groundwater and surface water pollution (construction and } \\
\text { pavement drainage), specific traffic accidents }\end{array}$ \\
\hline 3. Soil & loss, erosion, contamination \\
\hline 4. Nuisance & noise, vibrations \\
\hline 5. Aesthetics & Landscape degradation, visual intrusion \\
\hline $\begin{array}{l}\text { 6. Ecological } \\
\text { severance }\end{array}$ & $\begin{array}{l}\text { flora \& fauna degradation, deforestation, ecologic division of } \\
\text { sensitive ecosystems, barrier effect }\end{array}$ \\
\hline 7. Cultural & Effects on historical \& archeological sites \\
\hline
\end{tabular}

The severity of environmental impacts greatly varies during the phases of a project. Table 2 provides an estimation of that severity. It should be mentioned that, frequently, environmental impacts during construction are underestimated or ignored.

After the identification and appraisal of all possible environmental impacts, the means of acquiring and analyzing the required data should be determined. Data for environmental studies can be captured through satellite pictures, maps, aerial photographs and, certainly, by site visits and relevant measurements.

Then terrain model calculations are required and thereby appropriate thematic maps can be created. Raster map representation has certain advantages over the vector one. It simplifies spatial analysis through overlays, mathematical morphology based models and Boolean operations, which are all very useful in environmental analysis. The raster format is compatible with remote sensing and 
automated data capture technologies, which are important sources of environmental data. The conventional methods of impact assessments depict the output in the form of tables, graphs and so on. Thus, GIS technology is a valuable tool for analyzing the data for environmental assessment studies.

Table 2: $\quad$ Severity of environmental impacts during roadworks construction and operation.

\begin{tabular}{|l|c|c|}
\hline \multirow{2}{*}{ Environmental Element } & \multicolumn{2}{|c|}{ Project Phase } \\
\cline { 2 - 3 } 1. Air quality & Construction & Operation \\
2. Water & +++ & ++ \\
3. Soil & +++ & ++ \\
4. Noise and vibration & +++ & + \\
5. Aesthetics and landscape & ++ & +++ \\
6. Ecological severance & +++ & + \\
7. Cultural & +++ & ++ \\
\hline
\end{tabular}

key: +++: high, ++: medium, +: low

The environmental appraisal framework will be next outlined. The purpose of the framework is to make the environmental appraisal process more transparent and objective. It gives decision takers a clear, consistent and reliable basis on which to found their decisions about how trunk road schemes should proceed, or what modifications are required to ensure environmental protection.

In developing the environmental appraisal framework it should be first kept in mind the need to:

- understand the project and its priorities;

- identify a range of options; and

- appraise options and impacts to determine the extent to which they meet the Government's or Society's objectives, given the need for benefits to outweigh costs and to achieve value for money.

Simultaneously, the project (road) should be safe and stimulating to the users. Each impact of a road scheme can be expressed in the following ways:

- qualitatively - using words to describe the severity of the impacts; and

- quantitatively - using numbers to indicate the scale of the impacts.

It should be mentioned that many environmental effects are unpriced by nature: there is not clear market analysis, which evaluates environmentally damaging behavior in the sense of charging the related social cost to the cause of the damage. This inevitably leads to the over-exploitation of the underpriced environmental goods, thereby reinforcing the decay. Conventional economic wisdom teaches us that such negative externalities can be coped with by means of appropriate taxes and by means of prohibitions and regulations. This requires that Governments act as representatives of environmental interests. Society and local Authorities are always asked and their views also safeguard environmental issues. 


\section{Sustainability and environmental impacts}

As mentioned, any road transportation project should be designed and constructed ensuring sustainability as much as possible. The responses to mitigate environmental impacts should satisfy the following criteria.

- Feasible: proposals that satisfactorily meet environmental objectives must be attainable and viable.

- Satisfactory: that is they must meet identified environmental objectives. These objectives will have been identified in a variety of documents including the Environmental Impact Studies, the Environmental Terms and any other subsequent directives. These are the minimum objectives to be met and will usually be strategic.

- Minimal resources: solutions should not be over-reliant on resources both during construction and operation/maintenance. A poor, unfeasible solution will be greedy in its use of such resources. A classic example is the need for permanent or medium term irrigation of planting.

- Affordable: finally, solutions must be within acceptable budget limits.

Referring to the environmental impacts of Table 1, an explicit presentation follows for enhancing sustainable road projects. Every effort has been made to ensure that the framework includes all significant impacts. However, it is for the decision takers (Project Designers, Environmentalists and Ministry Officials) to appraise the relative weighting value to be put on each individual parameter.

\subsection{Air quality sustainability}

By air emissions we mean: carbon oxides (COx), various hydrocarbons (HC), nitrogen oxides (NOx), aromatic products, sulfur compounds and dust and other suspended particulates. Dust can be reduced by watering any relevant dustproducing work (construction phase).

Direct measurements or simulation models are available to evaluate air pollution (operation phase). For the simulation models, traffic volume, traffic composition, emission quantities, prevailing wind direction and topographic conditions are required.

Vehicle technology is a major aspect in the effort to reduce air-pollution. Telematic technology interacting with the drivers can also play an important role by informing drivers and affecting their traffic behaviour so as to reduce delays, emissions and fuel consumption. Telematics alone is widely acceptable by road users and can reduce air pollution by as much as $20 \%$, Nikolaou et al [3].

Airborne dust and other contamination such as gases can be effectively filtered by vegetation. Evergreen species perform better over the whole year as well as dense twiggy deciduous species, particularly those with large soft leaves.

\subsection{Water sources sustainability}

Surface water flow should remain unaffected by the construction of the road. This is relatively easy to attain by providing culverts even for the smallest ravine. 
In sensitive areas both surface and ground water should be protected from potential pollution. Tire remnants, leaching of fuel, oils by vehicles, spills of bitumen during construction, runoff of chloride substances as a result of deicing in winter, man-made wastes and pollution resulting from traffic accidents involving vehicles carrying fuels or toxic materials, are typical causes of water pollution.

Particular emphasis should be given to sensitive elements, which are:

- watercourses, ponds and lakes with fishes;

- watercourses with low rates of flow in summer; and

- catchments areas for drinking water.

Conservation involves the channeling of pavement runoff water into sediment separators and oil-removal tanks, which may also collect any toxic pollutant in case of a traffic accident. Dissolved oxygen, $\mathrm{PH}$ level, conductivity and dullness are measured to monitor the quality of watercourses. Also, collection or recycling of used oils during the construction phase is imperative.

\subsection{Soil sustainability}

Soil preservation should also be an important parameter in all roadworks. It is evident that the steep bare cuts enhance erosion. Topsoil is never thrown away, but gathered separately and then spread over the slopes, to facilitate quick germination.

Experience shows once soil erosion has become established it is significantly more difficult and expensive to eradicate. It should be noted that:

- grass or close textured ground cover is the best form of preventative vegetation because of its tight and dense root structure (planting of individual shrub/trees is not effective); and

- grass cover should be established as soon as possible after the slopes have been formed with no slopes being left unprotected over the winter months.

\subsection{Non-nuisance sustainability}

Direct measurements or simulation models are available to evaluate noise and vibrations levels. For these simulation models approach traffic volume, traffic composition, distances, topography and type of terrain/flora are required.

Appropriate indices are used to evaluate noise annoyance, the most common is LeqA. The threshold which should not be exceeded is normally $65 \mathrm{db}(\mathrm{A})$ in front of housing units and $55 \mathrm{db}(\mathrm{A})$ during night-time. The main measure to ensure that the threshold is not exceeded is to provide sound barriers. The construction of resin-bonded pavements may reduce noise levels as well. Vehicle technology is also a major aspect in this effort, producing silent engines and more effective machine insulation. Also, a good way to reduce perceived noise is by thick vegetation which screens the noise source from the view of the listeners. Dense twiggy evergreen vegetation is best. 


\subsection{Landscape sustainability}

The main objective is to ensure that the general aspect of the landscape is changed as little as possible by the project. The various landscape elements should first evaluated, like features (valleys, rock outcrops, ravines), cover (pasture, fields, scrubs, wood), existing works (roads, buildings, quarries, pylons). Landscape assessment is, inevitably, qualitative.

Landscape preservation will first be a matter of solving engineering problems (principally, magnitude of cuts and fills) and then a matter of landscape work and revegetation. It is essential that revegetation should be kept within the existing landscape context, or, if alien styles were introduced, landscape integrity will be lost. Diminishing cuts and fills greatly helps in reducing cut surplus for disposal or fill demand. Diminishing cuts and fills practically means either that we can tolerate a lower standard road, or that we have to construct tunnels, bridges and viaducts, increasing dramatically the budget of the project.

Contacts with the local authorities should be made to determine the most environmentally appropriate sources of aggregates and fill material. Landscape parameters are involved in structures design as well, i.e. construction of bridges of high aesthetic value, which will be worthy to be seen.

\subsection{Ecological severance}

The construction of a road wounds the natural environment and affects the wild fauna of the area. Apart from the loss and fragmentation of the woodland, there is an indirect disturbance of the wildlife habitat as well. Lights, noise and odors produced by vehicles, expel animals farther away. A road also acts as a barrier. Provision of fauna passes alleviates wildlife habitat division. They can cross the road either underneath or over it (green bridges) and should coincide, if possible, with known animal routes. The most common and cheap alternative is the first one. This is achieved through a type of box culverts the floors of which are above any probable water flow level. Their height should be from $2-4.5 \mathrm{~m}$, depending on the size of the animal and their width is a function of the culvert length. Green bridges are preferable for large animals and should be at least $30 \mathrm{~m}$ wide with thick vegetation at the borders.

Special emphasis should be given to the identification of any vulnerable ecological element in the region. Probably, the construction period has to be reduced, or restriction should implement to the nature of works, thereby protecting hatching periods of vulnerable species. Construction of noise screens and avoiding lighting of small bridges, mitigate habitat disturbance. Finally, roads should be fenced, otherwise small animals are crushed and larger animals may (collide with vehicles and) cause accidents.

\subsection{Cultural}

Account for the archeological, historical and literary heritage must be taken. The wealth of archaeological sites is enormous in Greece and is not surprising that any road would pass close to a number of them. Although the temptation is 
to think that the proximity of these sites as merely a problem it can also be seen as opportunities to undertake relevant excavations to unveil the cultural heritage of the area at a cost of a controlled delay to some parts of the project.

The road projects should be designed to highlight such areas by providing viewpoints or access to them or by constructing parking and rest/recreation areas adjacent to relevant sites. That is why in Table 2 the environmental impacts of a project to cultural issues may be positive.

\subsection{Application case to Egnatia motorway}

Egnatia Odos is still the largest strategic road under design and construction in Europe. It has a length of $700 \mathrm{~km}$, with 2.000 bridges, tunnels and passes through a broad range of landscapes many of which are of high value.

Specific Landscape Guidelines (OSAT [4]) have been issued which try to raise awareness of landscape issues in the designer's mind and to suggest a process by which solutions can be generated. OSAT comprise a Landscape Strategy for the whole road - the commitment to treat the landscape along the road corridor and associated link roads. The Guidelines are made for Egnatia motorway, but are applicable to other trunk roads as well.

Their first purpose is to provide a baseline record and understanding of the landscape context, into which the road will fit. This will assist the designers in assessing and anticipating specific landscape and environmental issues which may arise, both during construction and operation of the project. Specifically, the means for achieving objectives are as follows.

- a thorough understanding of the landscape through which the road passes; recognising the strengths and weaknesses, opportunities and threats in the landscape; a willingness to achieve integrated solutions which are appropriate to and reflect this landscape context.

- to minimise and mitigate environmental impacts of the road and its construction on the landscape, flora, fauna, local communities and heritage.

- to heal wounds and scars of the whole construction impact including associated quarries, disposal sites, work camps as well as the road verges in the minimum time by early restoration.

Egnatia motorway could threaten the existing landscape by the following typical effects on topography:

- major earthworks which remove surface cover and landscape fabric, subsequently needing wide-scale reinstatement;

- intrusion of the road into undisturbed, high quality landscapes with potentially severe, 'wounds and scars' which may be slow or difficult to treat and to achieve full restoration;

- additional land take needed to resolve cut/fill balances, possibly affecting adjacent sites of high environmental value;

- additional disruption and physical impacts of haulage routes between cut and fill sites with subsequent responsibilities for full reinstatement/restoration of disturbed areas; 
- intrusive embankments crossing valleys and low-lying land;

- cuttings which create scars on hillsides or notches in the skyline;

- surface instability resulting in surface erosion and loss of vegetation cover, failure to sustain regeneration; and

- unsympathetic junctions between new and existing roads.

In OSAT there are extensive guidelines to mitigate most adverse environmental effects. A typical example referring to the possible uses and threats of vegetation is subsequently outlined. Protection from high side wind gusts is a specific problem encountered to Egnatia. Well-designed tree shelter belts can reduce wind speeds considerably. To be effective they should:

- have a suitable species mix including dense shrubbery understorey and mainly evergreen tree species;

- be located in relation to principal threatening winds.

Generally shelter is provided for a distance downwind of the planting equivalent to 10 times the height of the trees and 4-5 times the distance upwind. However, vegetation in certain circumstances can be a potential hazard. These hazards may be:

- fire;

- hide the road (obstruct visibility);

- side obstacle (collision with trees);

- slippery pavement due to fallen leaves or due to ice patches resulting from the shade produced by trees planted at road sides; and

- fall of trees and branches during storms.

\subsection{Systemizing sustainability through Ministerial Decrees}

It is known that the stages within which the design of a work is completed are (mostly) three: reconnaissance, pre-study and definite study. The environmental impacts of a project have to be assessed at the earliest possible stage. For each specific project, just after its reconnaissance design study, its environmental study should be completed by an independent design team. The law demands that alternative designs for each specific project should be evaluated. The conclusions and specific terms are presented to the Ministry for approval. The Ministry for the Environment issues a Decree, which covers any major project or a project crossing environmentally sensitive areas. Documentary evidence is issued, known as 'land planning pre-approval', which is the official environmental license. The whole procedure makes allowances for the expression of the public opinion, especially of those groups which are going to be affected by the project.

The strict application of the Ministerial Decree is a prerequisite for the materialisation of the project. A brief description of a typical environmental Ministerial Decree [5] would be subsequently summarised.

- First, the type and the size of the activity would be determined. Then the vulnerable and specially protected elements of the environment of the region are determined. The period and extent for which the granted environmental provisions approval is valid is defined. The construction 
period and relevant restrictions according to the nature of works is defined.

- Special marginal values are set relative to noise and vibration levels and to the emissions and concentration of pollutants.

- Proper conservation and reuse of resources defined as necessary or imperative.

- Anti-pollution measures which might be taken to deal with the degradation of the environment are described.

- Dust-retaining equipment must only be used. Regular wetting of worksite roads, materials etc. should take place in order to reduce dust during earthworks. Only machinery and equipment having the suitable EU certificate can stay and work at the work-site.

- Fire protection measures should be taken during the operation of the machinery.

- The disposal of used lubricants and batteries on the ground is prohibited.

- Fauna passages should be provided to mitigate the adverse effect of land separation at least every i.e. $1000 \mathrm{~m}$. The existing forest road network has to be restored, wherever it is crossed by the project.

- The required excavations should be kept to the bare minimum. The disposal of any surplus material should be done at approved sites, which do not affect water surface flow, are not visible by the road and are at least $250 \mathrm{~m}$ away from any village, buildings and cemetery boundaries. In case material is required, it can be secured from legally operating quarries.

- The flow of surface water should be maintained unimpeded. A closed pavement drainage system has to be designed if required.

- Vegetation loss/damage is inevitable during road construction, but it should be limited to the minimum through proper site protection and adoption of good working practices. Planting works are compulsory and included in contracts. Planting works should start the soonest possible and, if required, should be supported by irrigation facilities. The species to be planted are subject to the approval of the local forest Authorities. Reforestation at the borders of a forest may become a term of a contract, when due to the construction of a road, extensive deforestation occurs.

- All work site installations will be removed after the end of the project's construction works and the site should be restored.

The definitive design study of the project has to comply with the relevant Ministry Environmental Decree. The highway alignment can be modified only within a belt of $200 \mathrm{~m}$ from the approved road centreline; if a major modification is required, then a new environmental impact study should be conducted.

\section{Conclusions}

Environmental problems are inherent in all major technical works. The appropriate framework should exist to safeguard and maintain most 
environmental parameters so that sustainable development is attained. The purpose of the framework is to make the environmental appraisal process more transparent, comprehensive and effective with particular emphasis to sustainability parameters. Explicit documentary evidence should exist, known as Environmental Ministerial Decree. The strict application of the Decree is a prerequisite for the materialisation of the project.

Generally, the policy on the environmental impact of major transportation projects should have three discrete strands:

- to give particular weight to the physiology of sensitive aspects, first by by-passing them or by making up for any adverse effect;

- to reduce the impact during the construction of the project; and

- to reduce the impact of operation traffic on the natural environment.

It is clear that a robust pro-environmental policy is expensive. Most engineering projects have more or less adverse environmental effects. To alleviate these effects and ensure sustainable development, certain design parameters of the projects should be modified and all these modifications are costly.

\section{References}

[1] Trademco, S.A., Trias, S.A., Study for the development of a system for the collection and processing of traffic counts in Egnatia road, Egnatia Road S.A, 2001.

[2] Kokkalis, A. \& Basbas, S., Environmental Provisions for Transportation Projects in Greece, Journal of Environmental Protection and Ecology, 1, No. 3, pp. 267-274, 1999.

[3] Nikolaou, K., Toskas, G., Basbas, S. \& Mustafa, M., Air Quality, Urban Transport Evolution and Application of Cross-Sector Telematics in Thessaloniki, Proc. of the 6th International Conference on Environmental Science and Technology, Global NEST-University of the Aegean, Samos, Vol.B, pp.291-298, 1999.

[4] OSAT: Landscape Restoration of Egnatia Odos and the specialised appendices, Egnatia Road S.A, (last appendix 2002).

[5] Environmental Ministerial Decrees, Ministry for the Environment, the Planning and the Public Works, Athens, Greece. 